\title{
Combination treatment with flavonoid morin and telomerase inhibitor MST-312 reduces cancer stem cell traits by targeting STAT3 and telomerase
}

\author{
SEYUNG S. CHUNG ${ }^{1,3}$, BRYANT OLIVA ${ }^{1}$, SAMI DWABE ${ }^{1}$ and JAYDUTT V. VADGAMA ${ }^{1-3}$ \\ ${ }^{1}$ Division of Cancer Research and Training, Department of Internal Medicine, \\ Charles R. Drew University of Medicine and Science; ${ }^{2}$ Jonsson Comprehensive Cancer Center \\ and ${ }^{3}$ David Geffen UCLA School of Medicine, Los Angeles, CA 90059, USA
}

Received February 18, 2016; Accepted April 26, 2016

DOI: 10.3892/ijo.2016.3546

\begin{abstract}
Colorectal cancer(CRC) is one of the mostcommonly diagnosed cancers worldwide. The malignant CRC that undergoes metastasis in the advanced stage is usually refractory to existing chemotherapy and shows a poor prognosis. However, to date, efficient targeted-therapy for metastatic CRC is illdefined. We tested the hypothesis that combined treatment of flavonoid morin and telomerase inhibitor MST-312 may reduce the cancer stem cell (CSC) traits. To characterize CSC phenotype, we performed the CD133/CD44 subpopulation profiling, tumorsphere formation assay, cell invasion assay and wound healing assay. We have examined the augmenting effects of the combined treatment of morin and MST-312 for 5-FU (5-fluorouracil) efficacy in human colorectal cancer. Morin and MST-312 combined treatment reduced CD133 (+) and CD44 (+) subpopulations in human colorectal and breast cancer cells, respectively. Tumorsphere formation and cell invasiveness were decreased with the morin and MST-312 combination treatment. Consistent with these data, morin and MST-312 treatment decreased the wound healing capacity of human breast cancer cells. Stress and apoptosis antibody arrays revealed that there were specific upregulated and downregulated proteins resulting from different treatments. Phosphorylation levels of BAD, p53 and Chk1 were enhanced upon morin/MST-312 treatments in HT-29 cells, whereas caspase-3 cleavage level and expression of IкB $\alpha$ were downregulated by combined morin/MST-312 treatment in SW620 cells. Finally, morin and MST-312 co-treatment further augmented the 5-FU efficacy, chemosensitizing the 5-FU resistant human colorectal cancer cells. Taken together, our study suggests that novel targeted-therapy can be implemented
\end{abstract}

Correspondence to: Dr Seyung S. Chung, Division of Cancer Research and Training, Charles R. Drew University of Medicine and Science, 1731 East 120th Street, Los Angeles, CA 90059, USA E-mail: seyungchung@cdrewu.edu

Key words: cancer stem cell, telomerase, combination treatment, colorectal cancer, STAT3 by using flavonoid morin and telomerase inhibitor MST-312 for improved cancer prognosis.

\section{Introduction}

Colorectal cancer (CRC) is the third most common cancer in men and the second in women worldwide, accounting for approximately 608,000 deaths worldwide (1). The most common cause of death from CRC is hepatic metastasis. Approximately $50 \%$ of CRC patients are diagnosed with hepatic metastases, either at the time of initial presentation or as a result of disease recurrence (2). However, there have been no major advances in the treatment of metastatic CRC during the last four decades. Multiple new FDA-approved therapies were tried, the 5-year survival remains extremely poor. Conventional chemotherapy efficiently targets tumor bulk, but there exists a small subpopulation of cells that contributes to resistance to chemotherapy and tumor regrowth. These cells are termed cancer stem cells (CSCs). Cumulative evidence has established that the majority of tumors comprise a population of CSCs responsible for the initiation and maintenance of tumors and resistance to cytotoxic drugs (3).

Signal transducer and activator of transcription 3 (STAT3) is a latent cytoplasmic transcription factor that conveys various cytokine and growth factor signals from the cell membrane to the nucleus (4). It is involved in many cellular processes including proliferation, survival, and immune responses. The transient activation of STAT3 is tightly regulated under normal conditions (5). In a variety of human malignancies, constitutive activation of STAT3 is correlated with tumor progression and poor prognosis (6). Recent reports showed that the STAT3 pathway preferentially regulates CSC self-renewal, tumor initiation, and metastasis in many solid tumors (7-9). It was also reported that the STAT3 pathway blockade causes a decrease in CSCs and a significant reduction of tumor formation in mouse xenograft models (10). Earlier studies indicated that STAT3 can be an excellent cellular target for anticancer agent development. However, STAT3 has generally been considered in practice to be non-targetable, and the lag in developing effective STAT3 inhibitors contributed to the current lack of FDA-approved STAT3 inhibitors. Here, we investigated 
whether targeting STAT3 with flavonoid morin, and targeting telomerase with MST-312, can reduce the cancer stem cell subpopulation in human colorectal and breast cancers.

Telomerase lengthens telomeres in DNA strands. A number of clinical cases reveal that telomerase is specifically activated in numerous human malignancies including colorectal cancer (11). There is a report that the prognosis of colorectal cancer patients with high telomerase activity was significantly worse than that of patients with moderate or low telomerase activity $(\mathrm{P}<0.01)(12)$. In the study, among the 87 patients with surgically resectable and potentially curable tumors, the disease-free survival rate of those with high telomerase activity was significantly poorer. These data suggest that inhibitors of telomerase may prove efficacious in treating patients with advanced disease. Recently, hTERT (human telomerase reverse transcriptase) was shown to contribute to the epithelial-mesenchymal transition and cancer stem cell traits in gastric cancer (13). Altogether, a growing body of evidence suggests that telomerase can be a good candidate as a cellular target for CRC therapy.

Morin (3,5,7,2',4'-pentahydroxyflavone) is a polyphenol compound originally isolated from members of the Moraceae family such as mulberry figs and old fustic (Chlorophora tinctoria). Earlier studies have shown that morin suppresses the proliferation of a wide variety of tumor cells including oral squamous cell carcinoma, leukemia, and COLO205 colorectal cancer cells in nude mice (14). Notably, the antitumor effect of morin is mediated through the inhibition of $N F-\kappa B$ and STAT3 transcription factors and their regulated genes $(15,16)$. Morin inhibits STAT3 tyrosine 705 phosphorylation in tumor cells through activation of SHP1 protein tyrosine phosphatase. MST-312 (telomerase inhibitor IX) is a synthetic compound that acts as a reversible telomerase inhibitor (17). MST-312 was also shown to have strong anti-proliferative effects on lung cancer stem cells (18).

We have demonstrated that the activated STAT3 transcriptionally upregulates hTERT (human telomerase reverse transcriptase) expression, and consequently promotes CSC traits in aggressive human breast cancers (19). This is in agreement with the recent finding that telomerase acts as a transcriptional modulator of the Wnt- $\beta$-catenin signaling pathway in stem cells and cancer cells $(20,21)$. The STAT3telomerase signaling axis is likely driving the CSC phenotype in human cancers. In this study, we investigated whether combination treatment with morin and MST-312, dually targeting STAT3 and telomerase, can reduce the CSC populations. We also tested whether the morin/MST-312 combination treatment could abolish tumorsphere formation and enhance 5-fluorouracil efficacy in human cancer cells originally resistant to 5-FU treatments. Finally, we tried to determine the cell stress and apoptosis gene signatures that were upregulated or downregulated upon morin/MST-312 treatments. This study focused on STAT3 and telomerase as potential therapeutic targets based on their significant roles in the colorectal cancer growth and maintenance.

\section{Materials and methods}

Cancer cell lines. HT-29, SW620 and MDA-MB-231 cancer cell lines were purchased from the American Type Culture
Collection (ATCC, Manassas, VA, USA). They were maintained in a monolayer culture in DMEM/F12 (Dulbecco's modified Eagle's medium) with $10 \%$ fetal bovine serum, $2.5 \%$ L-glutamine and $0.5 \%$ penicillin/streptomycin.

Reagents. Morin hydrate (Sigma-Aldrich, St. Louis, MO, USA; catalog no. M4008) and MST-312 (Sigma-Aldrich; catalog no. M3949) was purchased from Sigma-Aldrich Co. Morin was prepared in $50 \mathrm{mM}$ stock solution and MST-312 was in $10 \mathrm{mM}$ stock solution. The working concentration for morin was $50 \mathrm{mM}$ whereas $10 \mathrm{mM}$ for MST-312. Morin and MST-312 were either used alone or in combination throughout this study.

Tumorsphere formation assay. Matrigel (BD, Cambridge, MA, USA), $200 \mathrm{ml}$ was spread as a thick layer on wells of a 24-well plate and allowed to polymerize at $37^{\circ} \mathrm{C}$ for $15 \mathrm{~min}$. Cancer cells $\left(2 \times 10^{4}\right)$ grown in monolayer were trypsinized to single cells and plated on top of the pre-coated Matrigel. Plates were incubated at $37^{\circ} \mathrm{C}$ to allow cells to fully settle down before media was replaced with appropriate culture media containing 5\% Matrigel. Cells were grown for 15 days; fresh growth media with Matrigel was replenished every two days. Images of representative fields were taken.

Cell invasion assay. Mouse fibroblasts (NIH-3T3) were used as a chemoattractant, and grown in a 24-well plate in $2 \mathrm{ml}$ of the DMEM/F12 media. Boyden chambers were prepared with $25 \mu \mathrm{l}$ of 1:6 diluted Matrigel and allowed to incubate for $2 \mathrm{~h}$ to solidify. Each chamber received a different treatment: untreated, morin only, MST-312 only and morin plus MST-312. After cell synchronization, invasion was allowed to occur for $40 \mathrm{~h}$. The cells were then fixed with $0.5 \%$ glutaraldehyde and stained with $5 \%$ toluidine blue for cell counting. Three different 40x microscope fields were used to quantify the invasion statistics when counting cells.

Western blot analyses. Monolayer cultures of respective cell lines at $80-90 \%$ confluence were lysed using $100 \mu \mathrm{l}$ of RIPA buffer (Thomas Scientific Inc. Swedesboro, NJ, USA). Tris-glycine (Bio-Rad, Irvine, CA, USA) gels were loaded with 50-100 $\mu \mathrm{g}$ of lysates. After electrophoresis, the gel was transferred to a nitrocellulose membrane for $2 \mathrm{~h}$. The membrane was blocked for $1 \mathrm{~h}$ in $5 \% \mathrm{BSA}$ or $5 \%$ skim milk at $4^{\circ} \mathrm{C}$. The membrane was then washed 3 times with $1 \mathrm{X}$ TTBS and incubated overnight with the primary antibody at $4^{\circ} \mathrm{C}$. Primary antibodies of STAT3, pSTAT3 and $\beta$-actin were purchased from Cell Signaling Technology (Danvers, MA, USA). After incubation with the secondary antibodies conjugated with horseradish peroxidase (HRP), the protein bands were developed with the chemiluminescent reagents.

Telomerase activity assay. Cells were processed according to the manufacturer's protocol for the TeloTAGGG Telomerase PCR ELISA kit (Roche, Orange, CA, USA. catalog no. 11854666910). Briefly, cell pellets were thawed in lysis reagent, incubated on ice for $30 \mathrm{~min}$, and centrifuged at 16,000 $\mathrm{g}$ for $20 \mathrm{~min}$ at $4^{\circ} \mathrm{C}$. Telomerase activity was immediately measured in the resultant supernatant using the telomeric repeat amplification protocol in which telomerase, if present in the cell lysate, 
adds telomeric repeats to the $3^{\prime}$ end of a biotin-labeled synthetic P1-TS primer. Samples were amplified by polymerase chain reaction (PCR), with P1-TS and P2 primers creating an elongated telomere. The PCR product was denatured and hybridized to a digoxigenin-labeled probe that detects telomeric repeats in a subsequent enzyme-linked immunosorbent assay (ELISA). Samples were considered positive for telomerase activity if the ELISA resulted in a background-corrected absorbance of $\geq 0.2 \mathrm{U}$, resulting in binary positive/negative data. Telomerase assays were performed three times independently and P-values $<0.05$ were considered statistically significant.

FACS profile analysis. Approximately 500,000 colorectal cancer cells were washed with $1 \mathrm{X}$ PBS, trypsinized, and then transferred to a $15-\mathrm{ml}$ tube. Cell suspensions were centrifuged, re-suspended in $2 \mathrm{ml} 1 \mathrm{X}$ PBS, and then divided into two tubes of $0.5 \mathrm{ml}$ each. One tube was used as an unstained control and the other was stained with $5 \mu \mathrm{l}$ CD44 antibody (FITC Green; BD Biotech, San Jose, CA, USA) or CD133 antibody (PE Red; Miltenyl Biotec, San Diego, CA, USA). The tubes were vortexed briefly and incubated at room temperature for $15 \mathrm{~min}$ in the dark. Each tube was then washed with $3.5 \mathrm{ml}$ $1 \mathrm{X}$ PBS and then centrifuged for $6 \mathrm{~min}$. The supernatant was removed by aspiration, and the cells were re-suspended in $3 \mathrm{ml}$ $1 \mathrm{X}$ PBS and subjected to FACS profiling at the UCLA FACS Core Laboratory.

Stress and apoptosis antibody array. The Stress and Apoptosis Signal Antibody Array kit was purchased from Cell Signaling Technology (Cell Signaling Technology, Beverly, MA, USA; catalog no. 12856). Each CRC cell line had the following treatments in this order: untreated, morin only, MST-312 only, and morin plus MST-312. Whole protein lysates were prepared using the provided lysis buffer from the kit. One hundred milliliters of each lysate were placed onto the membrane window of the antibody slide. The treated slide was incubated overnight at $4^{\circ} \mathrm{C}$ on an orbital shaker. The slide was then washed with $100 \mathrm{ml} \mathrm{1X}$ array wash buffer and incubated on an orbital shaker for $5 \mathrm{~min}$ at room temperature. This procedure was repeated three more times. 1X Detection Antibody Cocktail (75 $\mu \mathrm{l}$ ) was added to each of the 16-wells and the plate was covered with the provided sealing tape. It was incubated for $1 \mathrm{~h}$ at room temperature on an orbital shaker. Next, three wash cycles were performed and the slide was incubated for 30 min with $75 \mu 1$ 1X HRP-linked streptavidin. The slide was washed and treated with Lumi Glo and peroxide. The Bio-Rad Gel Documentation system was used to take detailed pictures of the array using the Quantity One software using the ChemiDoc XRS function. ImageJ software was used to analyze the antibody array. All the array images were scanned and saved as JPEG files. We utilized the ImageJ software to quantify the expression levels of proteins. The quantified protein expression levels were presented as histograms with statistic significance.

Cell viability assay. The cell viability was evaluated by the 3-(4,5-dimethylthiazol-2-yl)-2,5-diphenyltetrazolium bromide (MTT) uptake method. Briefly, the 5-FU chemo-resistant cell lines, HT-29 and SW620, were seeded in a 96-well plate (1,000 cells per well) and exposed to different concentra- tions of 5 -FU or 5 -FU plus $5 \mu \mathrm{M}$ morin, or 5 -FU plus $3 \mu \mathrm{M}$ MST-312 in triplicate for $24 \mathrm{~h}$. Additionally, in another set of experiments, cells were co-treated with $5 \mu \mathrm{M}$ morin and $3 \mu \mathrm{M}$ MST-312 with different concentrations of 5-FU (0, 0.1, $1,2,3$ and $4 \mu \mathrm{M}$ ) for $24 \mathrm{~h}$ to obtain the optimum dose for combination treatment. Cells were washed twice with PBS and subsequently, MTT solution $(5 \mathrm{mg} / \mathrm{ml})$ was added to each well and the plate was incubated for $4 \mathrm{~h}$ at $37^{\circ} \mathrm{C}$. The 96 -well plates were wrapped with aluminum foil and gently swirled for $15 \mathrm{~min}$ at room temperature. The absorbance of the cell suspension was measured at $570 \mathrm{~nm}$. The data obtained were calculated and were represented as hundredth of survival relative to controls. This experiment was repeated 3 times independently, and statistical analysis was done to obtain the final values.

Statistical analysis. Student's t-tests were used to evaluate the significance of changes in all combination treatment assays compared to controls. Differences were considered statistically significant at $\mathrm{P}<0.05$.

\section{Results}

Morin inhibits STAT3 phosphorylation and MST-312 inhibits telomerase activity in human colorectal cancer cells. To confirm the molecular functions of morin and MST-312, we tested two colorectal cancer cell lines which contain the constitutively phosphorylated STAT3 (pSTAT3) and activated telomerase, HT-29 and SW620. Morin inhibits STAT3 phosphorylation in a dose-dependent and time-dependent manner (16). Initially, we treated HT-29 and SW620 cells with morin at the concentration $50 \mu \mathrm{M}$ for $24 \mathrm{~h}$. After the treatment, we ran a western blot analysis to examine STAT3 phosphorylation status. As shown in Fig. 1A, STAT3 phosphorylation was inhibited in both HT-29 and SW620 cell lines whereas total STAT3 expression levels remained the same (Fig. 1A). Our data suggest that morin specifically inhibited STAT3 phosphorylation step in colorectal cancer cell lines.

Next we wished to determine the telomerase activity in HT-29 and SW620 cell lines. MST-312 is a synthetic compound that functions as a reversible telomerase inhibitor (17). To monitor telomerase activity, TRAP-PCR-ELISA assay was performed as described in Materials and methods. HT-29 and SW620 were treated with morin alone at a concentration of $50 \mu \mathrm{M}$ for $24 \mathrm{~h}, \mathrm{MST}-312$ alone at a concentration of $10 \mu \mathrm{M}$ for $24 \mathrm{~h}$ and morin and MST-312 combination for $24 \mathrm{~h}$ and were applied to the telomere PCR-ELISA assays. As shown in Fig. 1B, MST-312 treatment inhibited telomerase activity, average absorbance was clearly decreased from 0.98 to 0.47 (OD, 490-750) whereas morin slightly reduced the absorbance from 0.95 to 0.90 in HT-29 (Fig. 1B). Morin and MST-312 combined decreased the absorbance to 0.35 . Similarly, MST-312 decreased the absorbance from 0.99 to 0.41 (OD, 490-750) while morin reduced it from 0.99 to 0.93 in SW620 cell lines. When morin and MST-312 were combined, telomerase activity was decreased to 0.24 . Our results confirm that MST-312 inhibited telomerase activity in human colorectal cancer cells and when combined with morin, the inhibitory effects were further enhanced. 
B

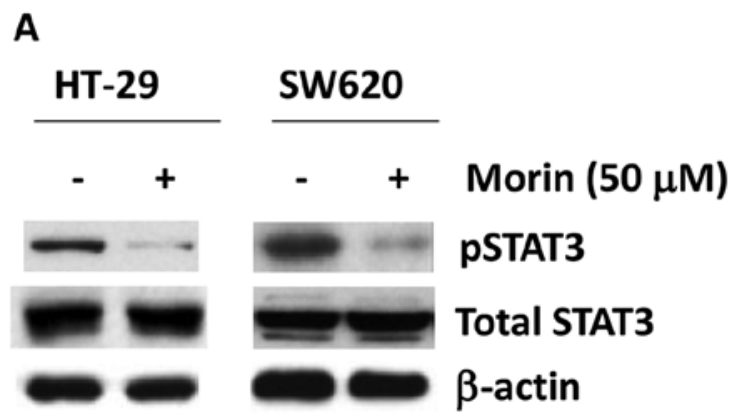

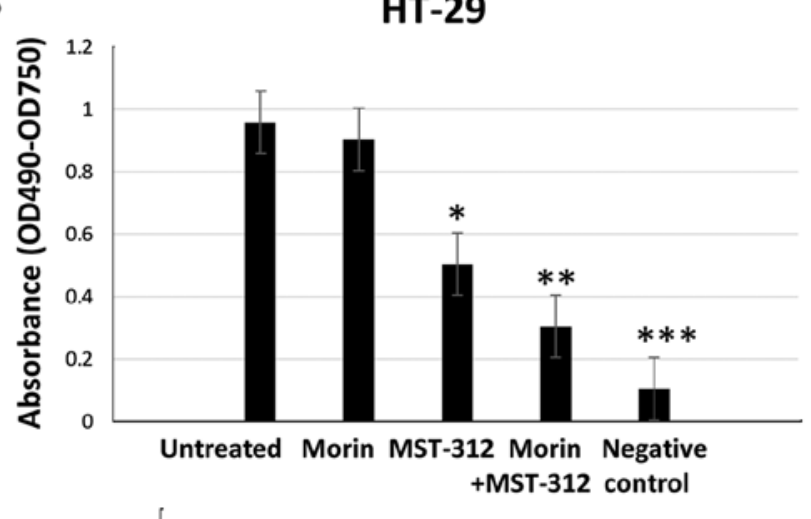

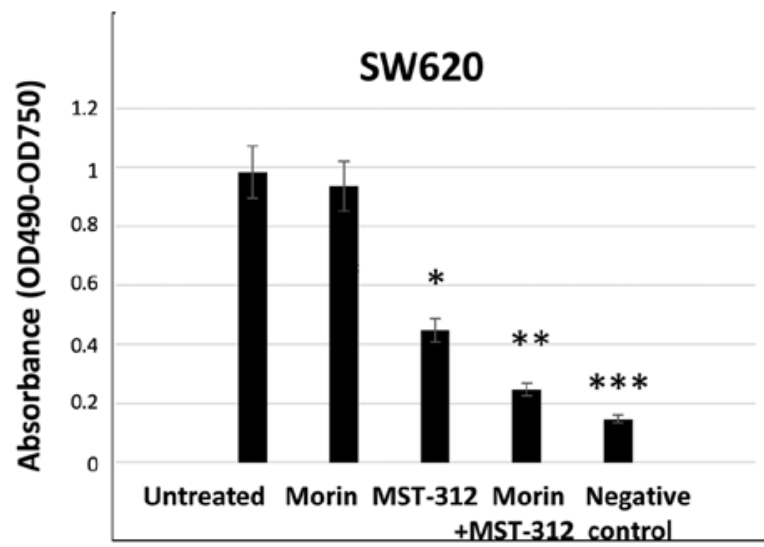

Figure 1. Morin inhibits phosphorylation of STAT3 and MST-312 decreases telomerase activity in human colorectal cancer cell lines HT-29 and SW620. (A) Western blot analyses of HT-29 and SW620 for pSTAT3 and total STAT3. Cells were treated with morin at $50 \mu \mathrm{M}$ for $24 \mathrm{~h}$ and subjected to protein analyses for pSTAT3 and total STAT3. (B) TRAP-PCR-ELISA assay for telomerase activity. HT-29 and SW620 were treated with morin at $50 \mu \mathrm{M}$ for 24 h, MST-312 at $10 \mu \mathrm{M}$ for $24 \mathrm{~h}$ and morin and MST-312 combination for $24 \mathrm{~h}$ and applied to TRAP-PCR-ELISA assay to monitor telomerase assay. Telomerase activities were measured three times independently. All of data are presented as mean $\pm \mathrm{SD}\left(\mathrm{n}=3\right.$ in each group). ${ }^{*} \mathrm{P}<0.05,{ }^{* * *} \mathrm{P}<0.01,{ }^{* * * *} \mathrm{P}<0.001$ vs. untreated control.

Combined treatment of morin and MST-312 show reduction of the CD133 (+) subpopulation from HT-29 and SW620 cells. To quantify the cancer stem cell population, we chose CD133 as a biomarker. FACS profiling revealed a clear reduction of the $\mathrm{CD}_{133}{ }^{+}$population in the cancer cells treated with morin and MST-312. Untreated HT-29 showed that $69.9 \%$ of cells were CD133 (+) (Fig. 2A). However, when we treated HT-29 with morin $(50 \mu \mathrm{M}$ for $24 \mathrm{~h}$ ), the CD133-positive subpopulation was reduced to $63 \%$ (Fig. 2B). Similarly, MST-312 treatment $(10 \mu \mathrm{M}$ for $24 \mathrm{~h})$ reduced the CD133 (+) population to $64.5 \%$ (Fig. 2C). Moreover, the CD133 (+) population was decreased to $57.9 \%$ after combined treatment with morin and MST-312 in HT-29 cells (Fig. 2D). Representative histograms are presented with the statistical significance.

We also observed the same CD133 (+) pattern from the metastatic colorectal cancer cell line SW620. In the untreated control SW620, $81.7 \%$ of cells were CD133 (+) (Fig. 2E). After treatment with morin $(50 \mu \mathrm{M}, 24 \mathrm{~h})$, the CD133 (+) population was reduced to $57.5 \%$ (Fig. 2F). With MST-312 treatment, CD133 (+) was decreased to $69.1 \%$ (Fig. 2G). Notably, the combined treatment of morin and MST-312 showed enhanced reduction of CD133 (+) to $55.5 \%$ (Fig. $2 \mathrm{H}$ ). Our results demonstrate that combined treatments with morin and MST-312 indeed reduced the CD133 (+) subpopulations in both primary and metastatic human colorectal cancer cell lines. Histograms of the CD133 (+) populations are presented with statistical significance.
Morin and MST-312 treatments abolish the tumorsphere formation and suppress cell invasiveness in human colorectal cancer cell lines. As combined treatment of morin and MST-312 reduced CD133 positivity, we next examined the celllevel invasiveness of the colorectal cancer cells. To this end, we employed two cell invasion assays, tumorsphere formation assay and boyden chamber assays. In tumorsphere culture condition, we created a three-dimensional microenvironment by adding 5\% Matrigel to the 24-well plates. As shown in Fig. 3, both HT-29 and SW620 cells formed tumorspheres in 7 days. However, when we treated cells with morin and MST-312, the tumorsphere forming capacity was significantly reduced. Untreated control HT-29 formed 32 tumorspheres per wells (Fig. 3A). However, when cells were treated with morin and MST-312, the formation was reduced to 15 and 21 tumorspheres, respectively. The combined treatment of morin and MST-312 abolished tumorsphere formation from HT-29. We observed a similar pattern in the SW620. Untreated control cells formed 45 tumor-spheres per wells (Fig. 3B). Morin treatment resulted in a reduction to 32 tumorspheres and MST-312 treatment a reduction to 21 tumorspheres per well. When we treated SW620 with morin and MST-312 together, tumorsphere formation capacity was abolished.

In agreement with the tumorsphere formation, cell invasion assays also revealed that combined treatment inhibited cell invasiveness. On average, the number of cells invading from the boyden chamber decreased from 55 to 2 when compared 
A

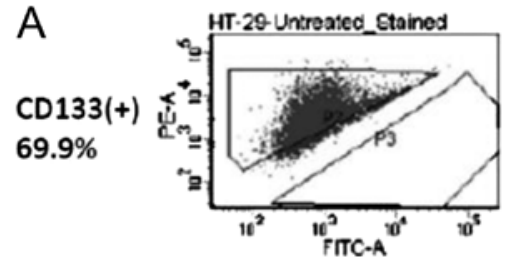

C $64.5 \%$

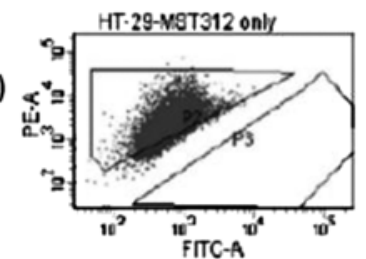

B $63.0 \%$

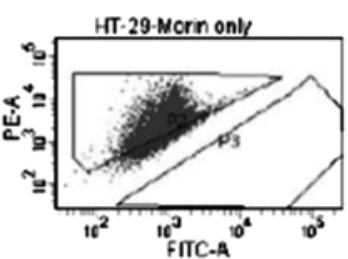

D

$\operatorname{CD} 133(+1$ $57.9 \%$

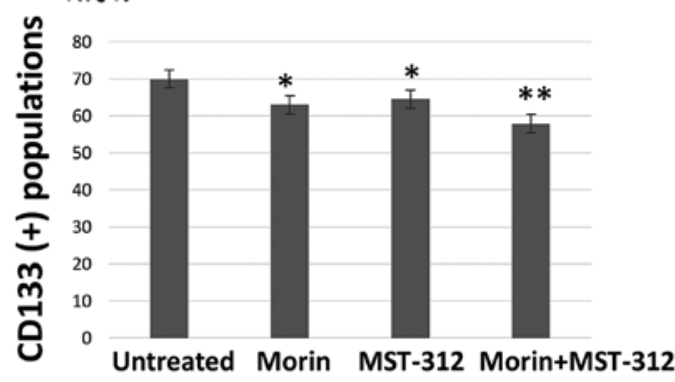

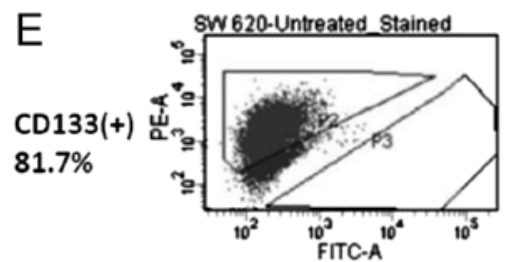

G

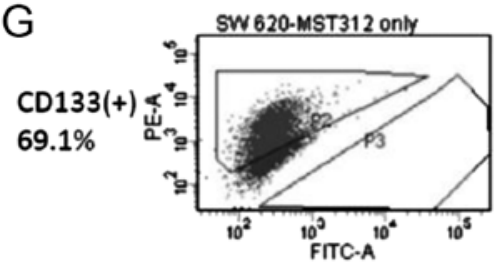

$\mathrm{F}$

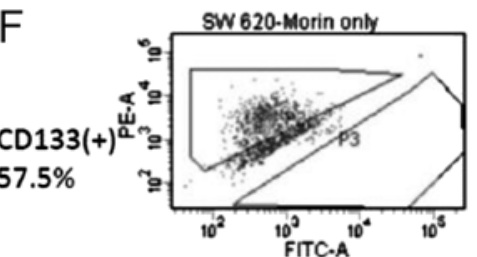

$\mathrm{H}$

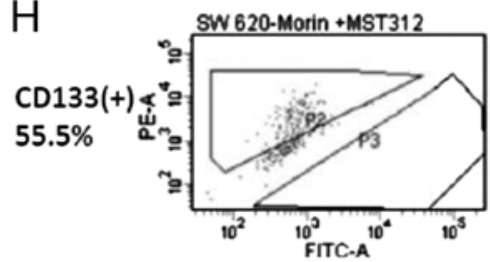

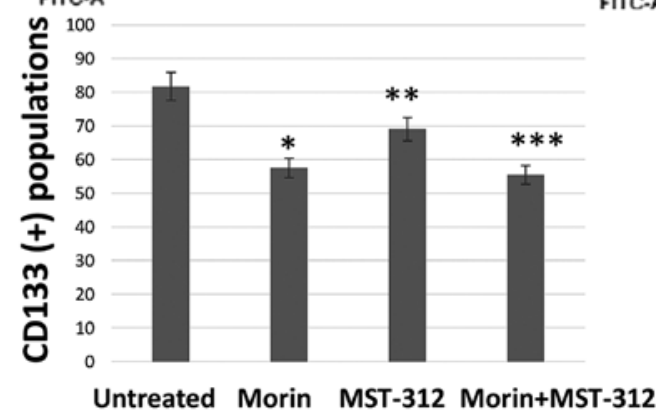

Figure 2. FACS profiling of HT-29 and SW620 for CD133 (+) with morin and MST-312 treatment. HT-29 and SW620 were treated with morin and MST-312, then subjected to FACS analyses for CD133 (+) monitoring. (A) HT-29 untreated control. (B) HT-29 was treated with morin alone at $50 \mu \mathrm{M}$ for $24 \mathrm{~h} . \mathrm{CD} 133(+)$ was monitored. (C) HT-29 was treated with MST-312 alone at $10 \mu \mathrm{M}$ for $24 \mathrm{~h}$, then CD133 (+) was monitored. (D) HT-29 was treated with morin and MST-312 combined at concentrations of 50 and $10 \mu \mathrm{M}$ for $24 \mathrm{~h}$, respectively. (E) SW620 untreated control. (F) SW620 was treated with morin alone at $50 \mu \mathrm{M}$ for $24 \mathrm{~h}$. CD133 (+) was monitored. (G) SW620 was treated with MST-312 alone at $10 \mu \mathrm{M}$ for $24 \mathrm{~h}$. (H) SW620 was treated with morin and MST-312 combined at concentrations of 50 and $10 \mu \mathrm{M}$ for $24 \mathrm{~h}$, respectively. Data are presented as mean $\pm \mathrm{SD}\left(\mathrm{n}=3\right.$ in each group). ${ }^{*} \mathrm{P}<0.05,{ }^{* *} \mathrm{P}<0.01,{ }^{* * * *} \mathrm{P}<0.001$ vs. untreated control.

to untreated control HT-29 and morin/MST-312-treated cells (Fig. 4A). In SW620, the average invaded cell numbers decreased from 75 of untreated control to 12 of morin/ MST-312-treated cells (Fig. 4B). Our results suggest that morin/MST-312 combined treatment can efficiently reduce the cancer stem cell subpopulations from human colorectal cancer cells.
Distinct stress and apoptosis-related gene expression patterns responding to morin and MST-312 treatments. The findings that morin and MST-312 treatment inhibited CSC phenotype suggest that it may directly trigger certain signaling pathways. Therefore, we wished to determine how morin and MST-312 treatments elicit cellular stress and apoptosis responses from colorectal cancer cells. To assess the net effects of the treat- 
A
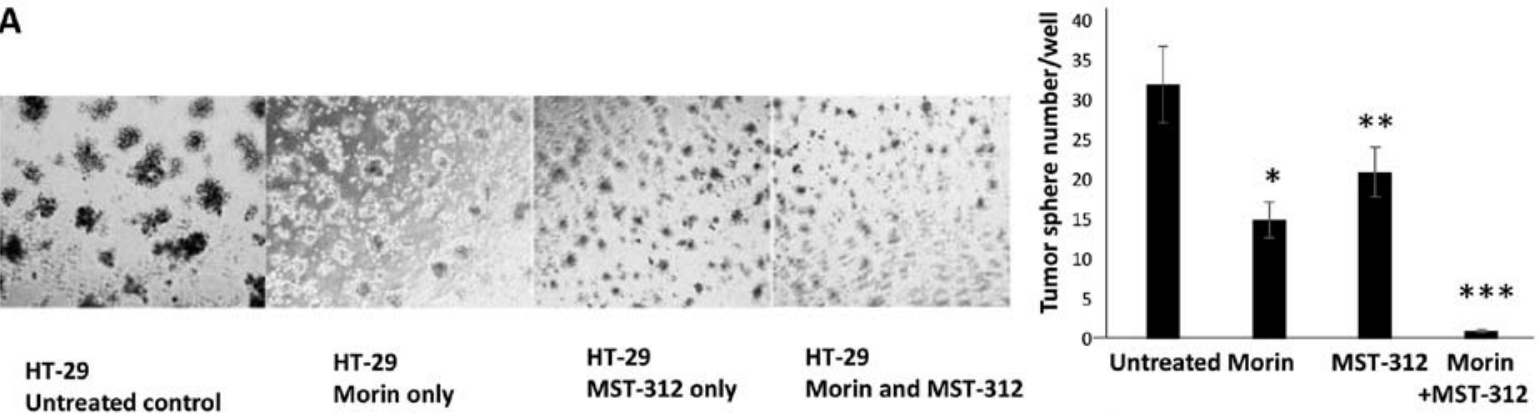

B

Untreated control

Morin only

MST-312 only

Morin and MST-312

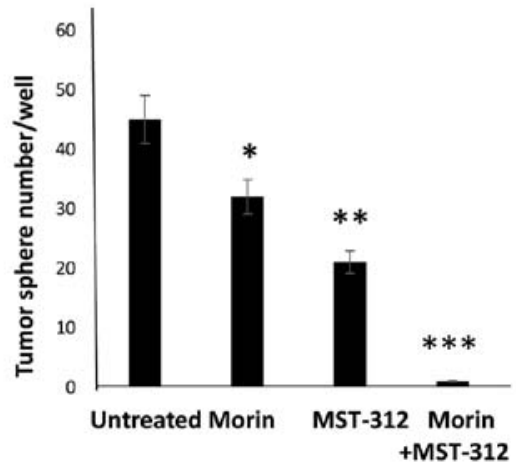

Figure 3. Inhibition of tumorsphere formation with morin and MST-312 treatment in HT-29 and SW620. Combined treatments of morin and MST-312 reduced tumorsphere formation capability from colorectal cancer cells. (A) HT-29 untreated control, pre-treated with morin alone at $50 \mu \mathrm{M}$ for $24 \mathrm{~h}$, pre-treated with MST-312 $10 \mu \mathrm{M}$ for $24 \mathrm{~h}$ and pre-treated with morin and MST-312 combination at concentrations of 50 and $10 \mu \mathrm{M}$ for $24 \mathrm{~h}$, respectively. Cells were cultured for 7 days. On the right side, graphic presentation of HT-29 tumor-sphere formation results. Data are presented as mean $\pm \mathrm{SD}$ ( $\mathrm{n}=3$ in each group). ${ }^{*} \mathrm{P}<0.05$, ${ }^{* *} \mathrm{P}<0.01,{ }^{* * *} \mathrm{P}<0.001$ vs. untreated control. (B) SW620 untreated control, pre-treated with morin alone at $50 \mu \mathrm{M}$ for $24 \mathrm{~h}$, pre-treated with MST-312 alone at $10 \mu \mathrm{M}$ for $24 \mathrm{~h}$ and pre-treated with morin and MST-312 combination at concentrations of 50 and $10 \mu \mathrm{M}$ for $24 \mathrm{~h}$, respectively. Cells were seeded onto 3 -D cultures and tumorsphere formation was observed. On the right side, quantitative graph of SW620 tumorsphere formation results were presented. Data are presented as mean $\pm \mathrm{SD}$ ( $\mathrm{n}=3$ in each group). ${ }^{*} \mathrm{P}<0.05,{ }^{* *} \mathrm{P}<0.01,{ }^{* * *} \mathrm{P}<0.001$ vs. untreated control.
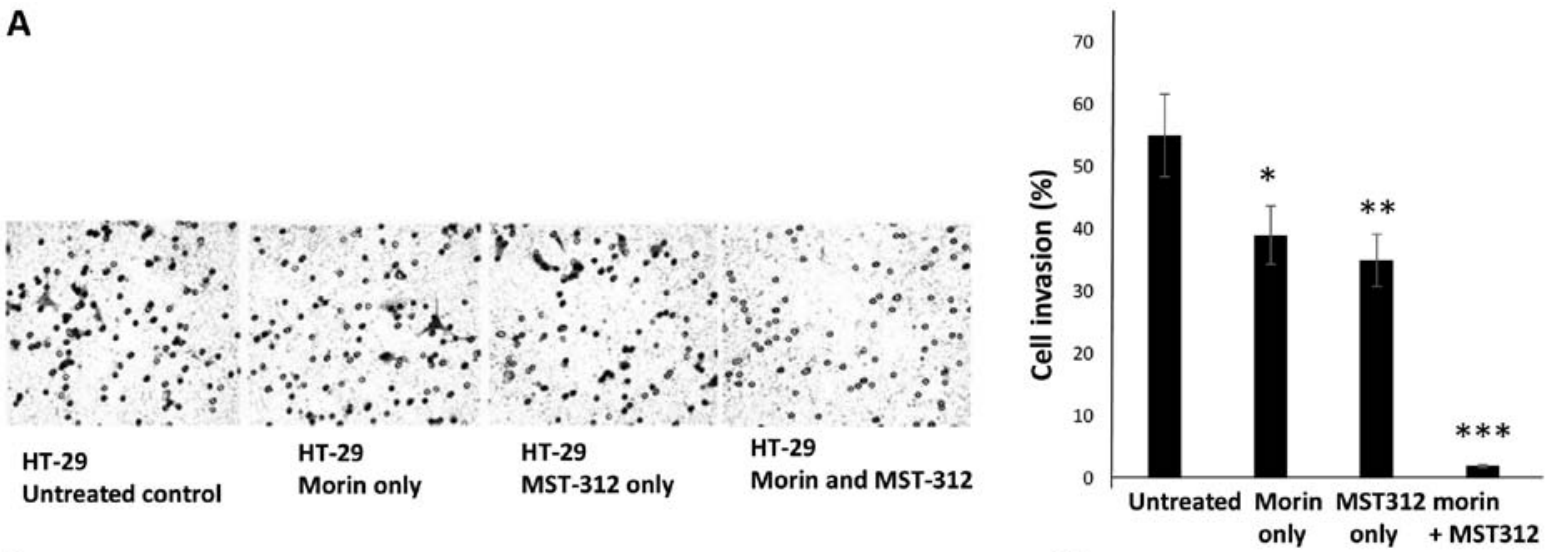

B
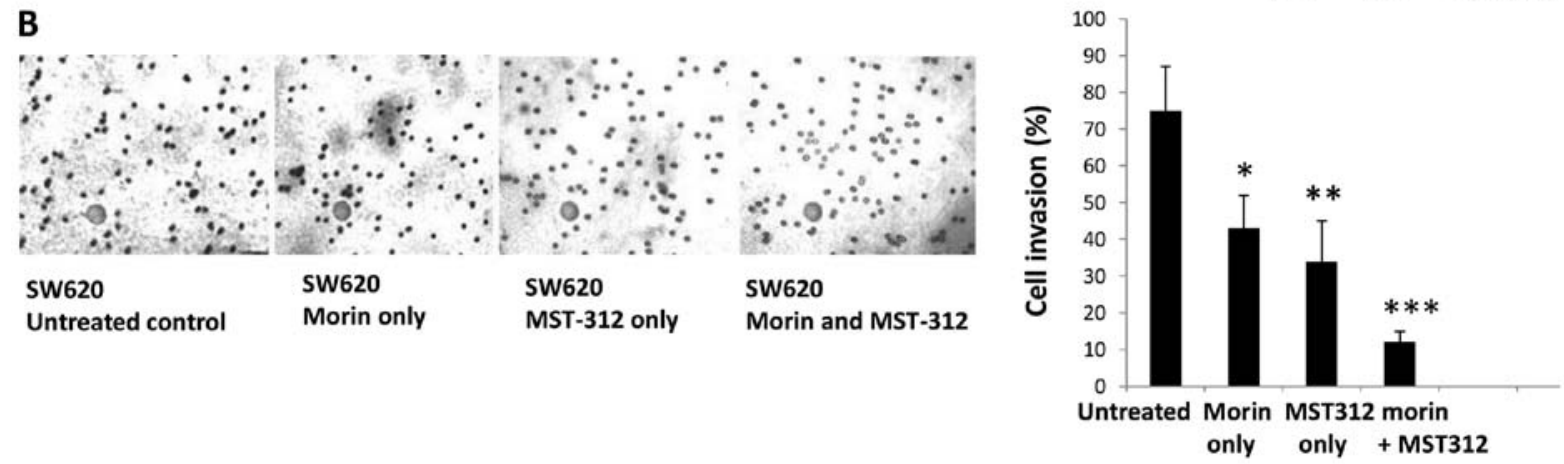

Figure 4. Decreased cell invasiveness with morin and MST-312 treatment in HT-29 and SW620. Cell invasiveness was examined by employing Boyden chamber assays. (A) HT-29 untreated control, pre-treated with morin alone, MST-312 alone and morin and MST-312 combination. On the right side, the cell invasion assay was quantitatively measured in graphic representation. Data are presented as mean $\pm \mathrm{SD}\left(\mathrm{n}=3\right.$ in each group). $\mathrm{P}<0.05$, ${ }^{* *} \mathrm{P}<0.01,{ }^{* * *} \mathrm{P}<0.001$ vs. untreated control. (B) SW620 untreated control, pre-treated with morin alone, MST-312 alone and morin and MST-312 combination. Cells were placed on the Boyden chamber and cell invasion was measured. On the right side, the cell invasion assay was quantitatively measured in graphic representation. Data are presented as mean $\pm \mathrm{SD}\left(\mathrm{n}=3\right.$ in each group). ${ }^{*} \mathrm{P}<0.05,{ }^{* * *} \mathrm{P}<0.01,{ }^{* * * *} \mathrm{P}<0.001$ vs. untreated control. 
A
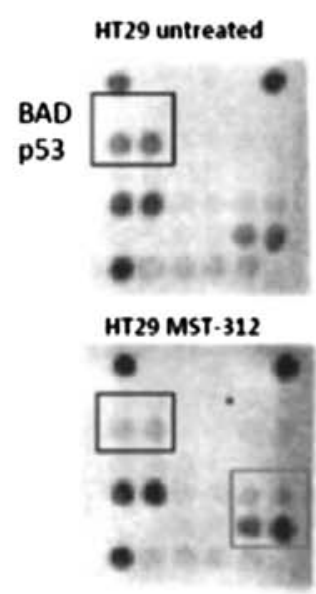

p53

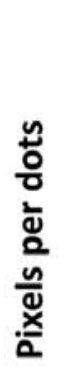

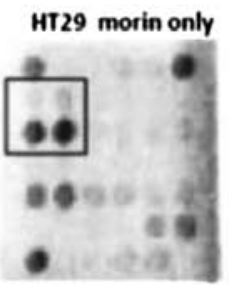

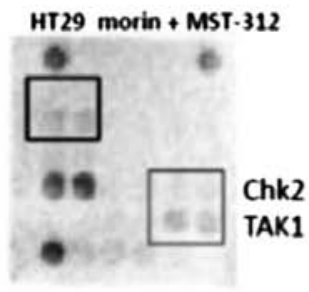

TAK1
B

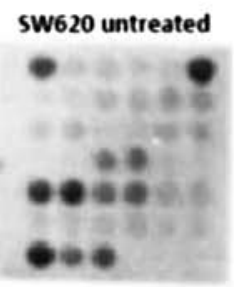

SW620 MST-312

Caspase-3 $\mathrm{I} \mathrm{KB} \alpha$

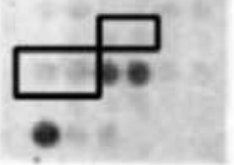

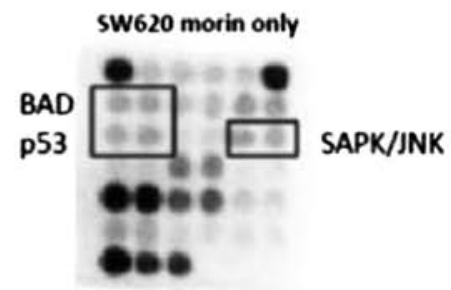

SW620 morin +MST-312

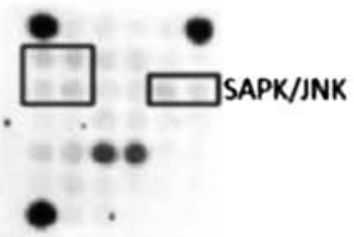

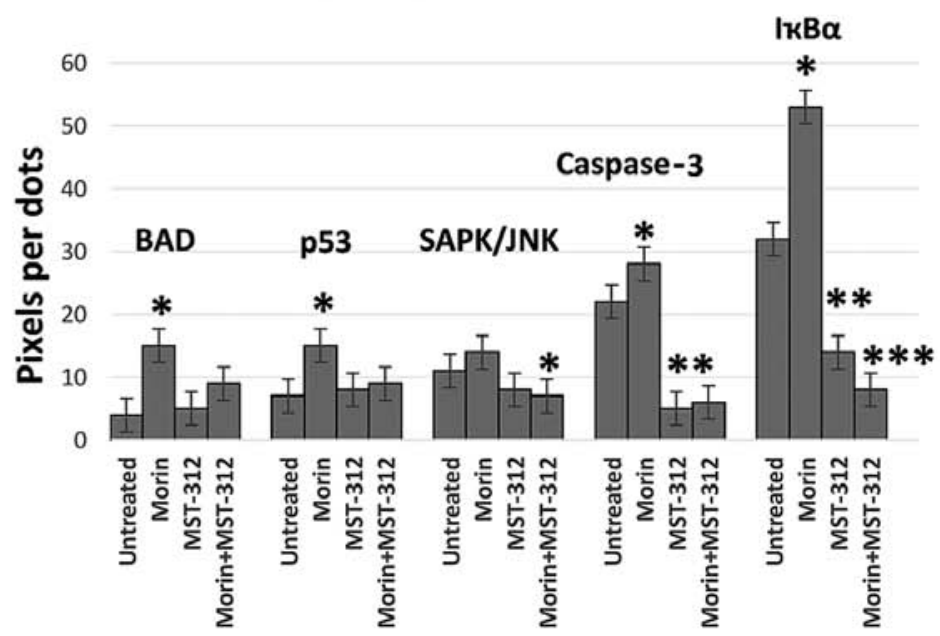

Figure 5. Cellular stress and apoptosis signaling antibody arrays of HT-29 and SW620. HT-29 and SW620 cells were treated with either morin/MST-312 alone or combined, then the key signaling components of stress and apoptosis were analyzed by antibody arrays. (A) HT-29 untreated control and treated with morin alone $(50 \mu \mathrm{M}$ for $24 \mathrm{~h})$, treated with MST-312 alone $(10 \mu \mathrm{M}$ for $24 \mathrm{~h})$ and treated with morin and MST-312 combination were applied to the cell stress and apoptosis arrays. Differentially expressed protein expression levels were presented as histograms with statistical differences. Data are presented as mean \pm SD (n=3 in each group). ${ }^{*} \mathrm{P}<0.05,{ }^{* *} \mathrm{P}<0.01,{ }^{* * * *} \mathrm{P}<0.001$ vs. untreated control. (B) SW620 untreated control, treated with morin alone (50 $\mu \mathrm{M}$ for $24 \mathrm{~h}$ ), treated with MST-312 alone (10 $\mu \mathrm{M}$ for $24 \mathrm{~h})$ and treated with morin and MST-312 combination were applied to the apoptosis array analyses. Differentially expressed protein expression levels are presented as histograms with statistical differences. Data are presented as mean $\pm \mathrm{SD}\left(\mathrm{n}=3\right.$ in each group). ${ }^{*} \mathrm{P}<0.05,{ }^{* *} \mathrm{P}<0.01$, ${ }_{* * * *} \mathrm{P}<0.001$ vs. untreated control.

ments, we decided to monitor the changes in key signaling components related to cellular stress and apoptosis. To this end, we utilized the stress and apoptosis signaling antibody array kit (Cell Signaling Technology). By using this array, we were able to simultaneously interrogate 19 signaling molecules that are involved in the regulation of stress response and apoptosis. Target-specific capture antibodies were spotted in duplicate onto nitrocellulose-coated glass slides. Cancer cell lysates were incubated on the slide followed by a biotinylated antibody. The expression differences from the antibody arrays were presented as histograms with statistical significance of the differential expression proteins in HT-29 and SW620. As shown in Fig. 5, morin treatment on HT-29 enhanced the levels of $\mathrm{BAD}$ and $\mathrm{p} 53$ phosphorylation (Fig. 5A). BAD is a member of the Bcl-2 family and a regulator of the programmed cell death pathway (22). Tumor suppressor p53 plays an important role in cellular responses to DNA damage (23). Thus, morin treatment activated BAD and p53 and concurrently induced apoptosis in HT-29 cells. MST-312 treatment inhibited p53 phosphorylation on the contrary, indicating that MST-312 inactivates p53, possibly independent of morin pathway. When morin and MST-312 were treated in combination, p53, Chk2 and TAK1 phosphorylation were inhibited in HT-29. Chk2 kinase acts downstream of ATM/ATR and plays an important role in DNA damage check point control (24). TAK1 is a kinase that can be activated by TFG- $\beta$, bone morphogenetic proteins and other cytokines (25). Morin treatment attenuated p53, Chk2 and TAK1 phosphorylation which are important for DNA damage control and cell survival. Increased apoptotic effects of morin and MST-312 treatments might be through the impaired DNA damage repair system and suppressed cell survival signaling.

Morin treatment on SW620 enhanced the phosphorylation of BAD, p53 and SAPK (Fig. 5B). SAPK kinase is activated through a dual phosphorylation of Thr202 and Tyr204 in response to pro-inflammatory cytokines and genotoxic stress (26). BAD and p53 activation with morin treatment is similar to HT-29. MST-312 treatment inhibited caspase-3 cleavage and 

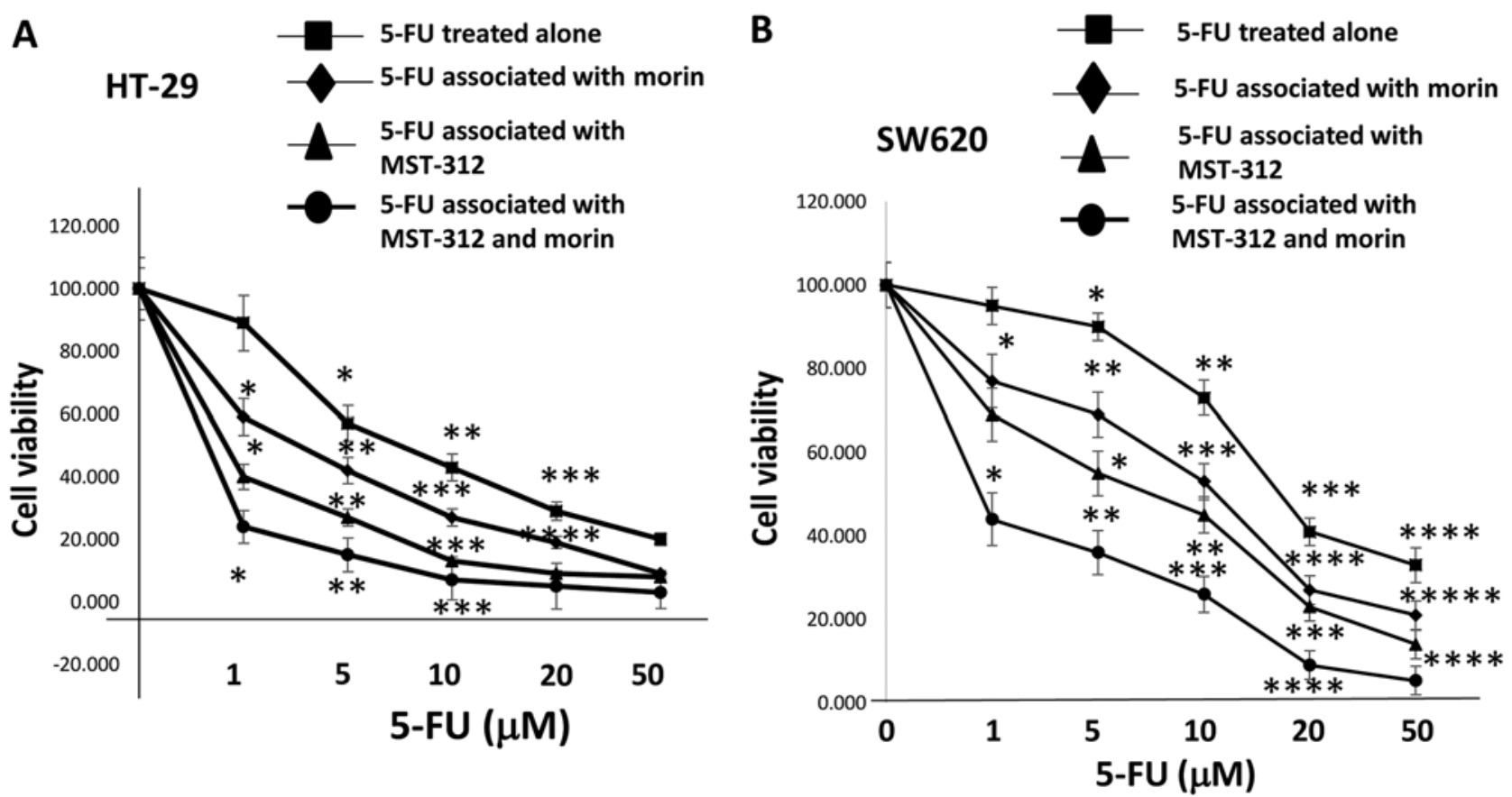

Figure 6. Cell viability is reduced by 5-FU, morin, MST-312 and the combination treatment in 5-FU-resistant cell lines HT-29 and SW620. Co-treatment with $5 \mu \mathrm{M}$ morin or morin and $3 \mu \mathrm{M}$ MST-312 combination chemosensitized drug-resistant colorectal cancer cells to 5-fluorouracil. (A) HT-29 was treated with different concentrations of 5-FU $(0,1,5,10,20$ and $50 \mu \mathrm{M})$ alone and associated with $5 \mu \mathrm{M}$ morin or $3 \mu \mathrm{M}$ MST-312 or morin and $3 \mu \mathrm{M}$ MST-312 combination. Cell viability was measured with the MTT method. The results are provided as mean values with standard deviations from at least three independent experiments. Data are presented as mean $\pm \mathrm{SD}$ ( $\mathrm{n}=3$ in each group). ${ }^{*} \mathrm{P}<0.05,{ }^{* *} \mathrm{P}<0.01,{ }^{* * *} \mathrm{P}<0.001$ vs. untreated control. (B) SW620 cell line was treated with different concentrations of 5 -FU $(0,1,5,10,20$ and $50 \mu \mathrm{M})$ alone or associated with $5 \mu \mathrm{M}$ morin or $3 \mu \mathrm{M}$ MST-312 or morin and $3 \mu \mathrm{M}$ MST-312 combination Data are presented as mean $\pm \mathrm{SD}\left(\mathrm{n}=3\right.$ in each group). ${ }^{*} \mathrm{P}<0.05,{ }^{* *} \mathrm{P}<0.01,{ }^{* * *} \mathrm{P}<0.001$ vs. untreated control.

downregulated I $\mathrm{B} \alpha$ expression level in SW620. Caspase-3 protease exerts a pro-apoptotic function through cleavage of multiple targets (27). Caspase-3 is activated at Asp175. ІкB $\alpha$ is targeted to the proteasome via phosphorylation at Ser32 and Ser36 (28). Morin and MST-312 combined treatment activated BAD, p53 and SAPK phosphorylation whereas inhibited caspase- 3 cleavage and IкB $\alpha$ phosphorylation in SW620. The enhanced apoptotic effects may be result from the inhibited cytokine signaling required for cancer cell survival. This distinct subset of gene inhibition in caspase- 3 cleavage and I $\mathrm{I} \mathrm{B} \alpha$ is possibly due to the cell line specific differences between HT-29 and SW620. Taken together, our data revealed the existence of distinct expression patterns from the stress and apoptosis genes responding to morin and MST-312 treatments in the colorectal cancer cell lines.

Morin and MST-312 co-treatments chemosensitized 5-FU resistant human colorectal cancer cells. Human colorectal cancer cell lines were sub-grouped based on their growth inhibition $\left(\mathrm{GI}_{50}\right)$ values against 5-FU treatments in a previous study (29). Three subgroups were chosen, consisting of 5-FU sensitive, intermediate and resistant colorectal cancer cell lines. Two 5-FU chemo-resistant cell lines, HT-29 and SW620, were used in our study to investigate the effects of morin/ MST-312 and/or 5-FU on cell viability. The $\mathrm{GI}_{50}$ values of HT-29 and SW620 were 14.90 and $17.97 \mu \mathrm{M}$, respectively. The cytotoxic effects of 5-FU or morin plus MST-312 on two colon cancer cell lines were determined using the MTT assay. The cancer cells were treated with different concentrations of
5-FU $(0,1,5,10,20$ and $50 \mu \mathrm{M})$ alone or combined with $5 \mu \mathrm{M}$ morin and $3 \mu \mathrm{M}$ MST-312. We observed that 5-FU blocked the proliferation of the cell lines HT-29 and SW620 in a dose-dependent manner with $5 \mu \mathrm{M}$ morin and $3 \mu \mathrm{M}$ MST-312 co-treatments (Fig. 6A). 5-FU efficacy was enhanced to the extent that the $\mathrm{IC}_{50}$ level was reduced to $0.5 \mu \mathrm{M}$ for HT-29 and $1 \mu \mathrm{M}$ for SW620 (Fig. 6B). Both 5-FU chemo-resistant cell lines became equally sensitive to 5 -FU with the co-treatment of $5 \mu \mathrm{M}$ morin and $3 \mu \mathrm{M}$ MST-312. Our data suggest that the morin/MST-312 combination treatment as an approach for the better treatment of human colon tumors with the potentially enhanced chemo-sensitivity to 5-FU.

Morin and MST-312 combination treatment reduced the CD44 (+) subpopulation and inhibited wound healing from human breast cancer cells. Morin and MST-312 treatment inhibited the CSC phenotype in human colorectal cancer cells. Next we wished to determine whether this effect holds true in other human cancers. To test this, we chose the human triple-negative breast cancer cell line, MDA-MB-231. It also contains constitutively activated STAT3 phosphorylated by JAK2 kinase at the site of Tyr705 (30) and activated telomerase. Morin (10 $\mu \mathrm{M}$ for $24 \mathrm{~h})$ and MST-312 (10 $\mu \mathrm{M}$ for $24 \mathrm{~h})$ were used alone or in combination. Untreated control and treated cells were subsequently applied to FACS analysis for CD44 (+) profiling (Fig. 7A). CD44 is a well-established biomarker for breast CSC population. When treatment was used, the CD44 (+) subpopulation was reduced slightly from $96.5 \%$ (CD $44^{+}$of the untreated control) to $92 \%$ (Fig. 7B). Similarly, 

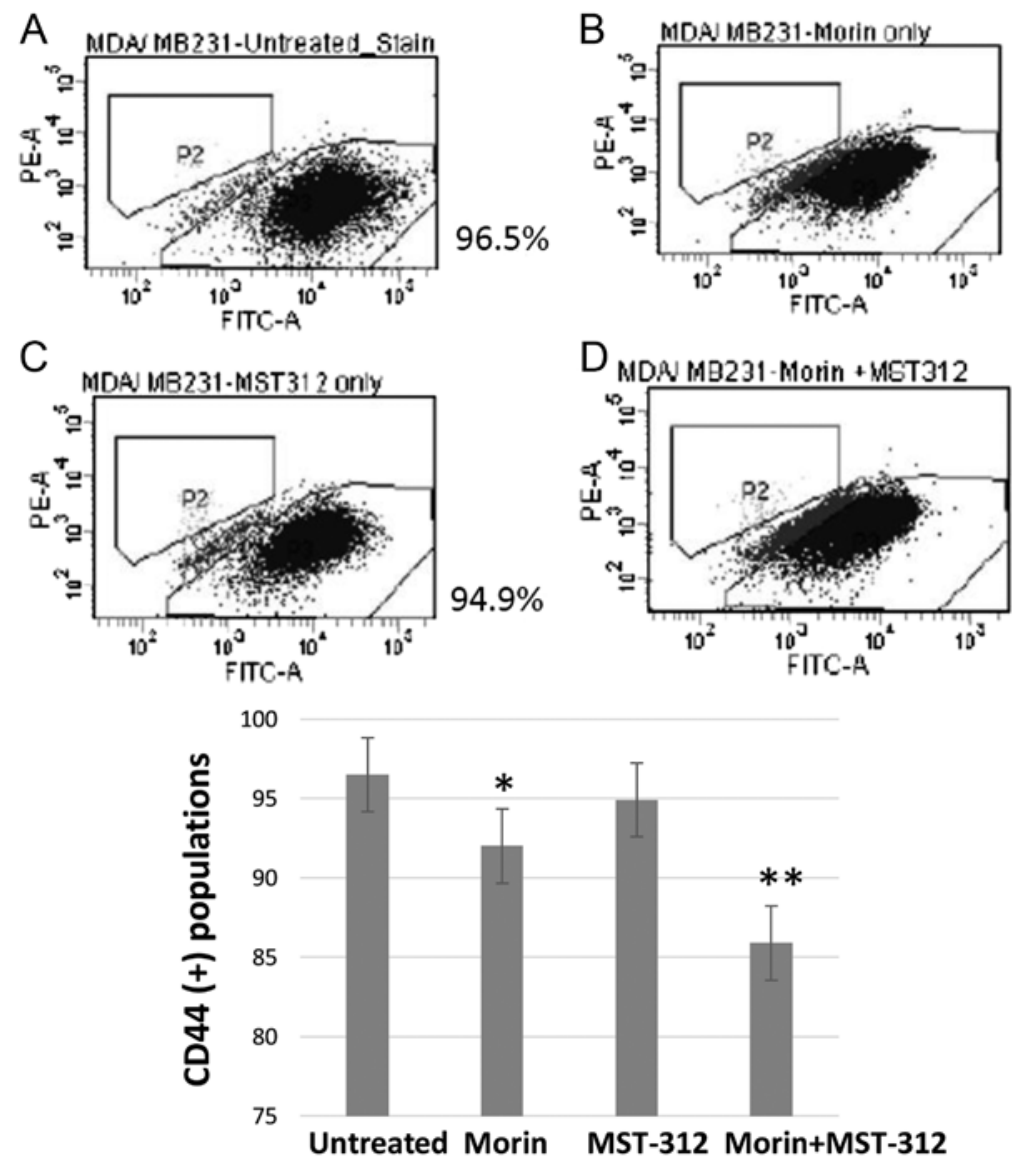

Figure 7. FACS profiling of MDA-MB-231 for CD44 (+) with morin and MST-312 treatment. The triple-negative breast cancer cell line MDA-MB-231 was treated with morin and MST-312, then subjected to FACS analyses for CD44 (+). (A) MDA-MB-231 untreated control. (B) MDA-MB-231 was treated with morin alone at $50 \mu \mathrm{M}$ for $24 \mathrm{~h}$. CD44 (+) was monitored. (C) MDA-MB-231 was treated with MST-312 alone at $10 \mu \mathrm{M}$ for $24 \mathrm{~h}$, then CD133 (+) was monitored. (D) MDA-MB-231 was treated with morin and MST-312 combined at concentrations of 50 and $10 \mu \mathrm{M}$ for $24 \mathrm{~h}$, respectively. Histograms are presented with statistical difference. Data are presented as mean $\pm \mathrm{SD}\left(\mathrm{n}=3\right.$ in each group). ${ }^{*} \mathrm{P}<0.05,{ }^{* * *} \mathrm{P}<0.01,{ }^{* * * *} \mathrm{P}<0.001$ vs. untreated control.
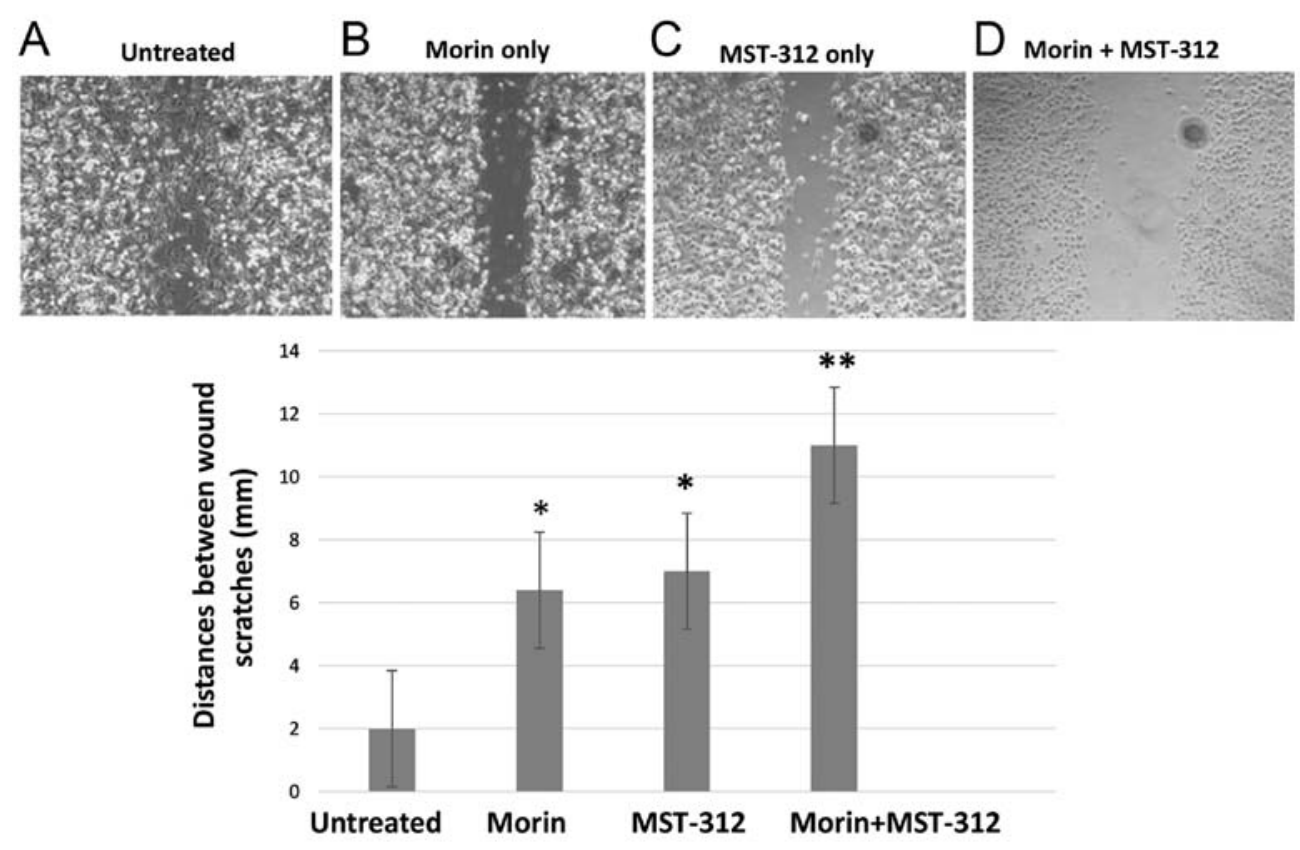

Figure 8. Wound healing assay for MDA-MB-231 treated with morin and MST-312. Morin and MST-312 treatment reduced the wound healing capability of breast cancer cells. (A) MDA-MB-231 untreated control $48 \mathrm{~h}$ after the wound induction. (B) MDA-MB-231 pre-treated with morin, $48 \mathrm{~h}$ after the wound induction. (C) MDA-MB-231 pre-treated with MST-312, $48 \mathrm{~h}$ after the wound induction. (D) MDA-MB-231 pre-treated with morin and MST-312 combined, $48 \mathrm{~h}$ after the wound induction. The distance between wounds was measured in three areas of cell cultures as means to quantify the cell migration. The histograms are presented with the statistically significant difference. Data are presented as mean $\pm \mathrm{SD}\left(\mathrm{n}=3\right.$ in each group). ${ }^{*} \mathrm{P}<0.05,{ }^{* * *} \mathrm{P}<0.01,{ }^{* * * *} \mathrm{P}<0.001 \mathrm{vs}$. untreated control. 
MST-312 treatment reduced the CD44 (+) population to $94.9 \%$ (Fig. 7C). The combined treatment with morin and MST-312 reduced the CD44 (+) to $85.9 \%$ (Fig. 7D). These data suggest that the synergism of morin and MST-312 may be conserved in multiple human cancers.

In agreement with FACS analyses, wound healing studies also showed synergistic effects of morin and MST-312 treatments. MDA-MB-231 cells were pre-treated with either morin/ MST-312 alone or in combination for $24 \mathrm{~h}$ at the same concentration (morin; $50 \mu \mathrm{M}$ and MST-312; $10 \mu \mathrm{M}$ ). Afterwards, the cells were seeded onto 24-well plates and strait scratches were performed. We observed wound healing up to $48 \mathrm{~h}$. As shown in Fig. 8, untreated control cells rapidly healed the wounds (Fig. 8A). However, morin and MST-312 treatments clearly inhibited the wound healing (Fig. 8B and C). The inhibition effect was enhanced upon morin and MST-312 combination treatment (Fig. 8D). Together, our results indicate that morin and MST-312 combination treatment can downregulate breast cancer stem cell phenotype.

\section{Discussion}

Cancer stem cells (CSCs) are considered to be responsible for the maintenance of the whole cancer cell population and tumor re-initiation after therapy. Considering the CSC traits, it is important to understand the signal pathways specifically activated in CSCs so that we can devise strategies to target them. This study is built on our previous findings that constitutively activated STAT3 upregulates hTERT expression and promotes cancer stem cell traits in human breast cancer. Subsequently, hTERT upregulated expression of the breast CSC marker, CD44. The STAT3-telomerase axis was selectively activated in cancer stem cell subpopulations.

In this study, we demonstrate that combined treatments of morin and MST-312 inhibit the cancer stem cell phenotype. We tested our hypothesis that flavonoid morin and telomerase inhibitor MST-312 co-treatments might result in an enhanced inhibition of cancer stem cell traits through dual targeting of STAT3 and telomerase. The colorectal CSC marker CD133 (+) subpopulation was reduced by the combination treatments. In accordance, tumor-sphere formation and cell invasiveness were decreased in the colorectal cancer cell lines.

To identify gene signatures responding to morin/MST-312 treatments, we studied the cellular stress and apoptosis antibody arrays. We identified specific subsets of genes that are upregulated and downregulated upon the combination treatments. Combined treatment of morin/MST-312 inhibited p53, Chk2 and TAK1 phosphorylation and enhanced apoptosis of the colorectal cancer cells. Since p53 and Chk2 both play roles in DNA damage check point control, the impaired DNA damage of the cancer cells likely led to cell death. TAK1 kinase is activated in TFG- $\beta$ and other cytokines. The cytokine signaling important for cancer cell survival was possibly suppressed by the morin and MST-312 in HT-29. There was caspase-3 and $\mathrm{I} \kappa \mathrm{B} \alpha$ inhibited cell death in SW620. Malfunctioning protein cleavage from caspase- 3 inhibition and disturbed targeting to the proteasome from I $\mathrm{B} \alpha \alpha$ might result in cell death in SW620 cells. The distinct subset of apoptosis genes exist in difference cancer cell lines, implicating differences in cell line characteristics. More colorectal cell lines and other cancer cell studies are warranted for the mechanistic work of morin and MST-312 in apoptosis and cell stress mechanism.

Morin and MST-312 combination treatments chemosensitized 5-FU-resistant human colorectal cancer cells. Since the STAT3-telomerase axis driven CSC phenotype is conserved in breast cancer, morin/MST-312 treatment also showed the same inhibitory effects against breast cancer stem cells.

Constitutively activated STAT3 has been reported in numerous human malignancies. Active STAT3 has been reported to participate in tumorigenesis by regulating the expression of genes involved in tumor cell proliferation, survival, invasion and metastasis (31). STAT3 activation also has been linked to chemo-resistance and radio-resistance $(9,32)$. We noted that constitutively activated STAT3 proteins are enriched in the CSC subpopulations. Mounting evidence suggests that STAT3 is an attractive therapeutic target for the development of anticancer stem cell agents.

Morin was originally isolated from members of the Moraceae family such as mulberry figs and old fustic. Earlier studies demonstrate that morin inhibits STAT3 phosphorylation at the Tyr705 site. We used morin at $50 \mu \mathrm{M}$ dosage because we observed that morin clearly suppressed constitutive pSTAT3 at that concentration in a gradient of $0,5,10,25$ and $50 \mu \mathrm{M}$ with human colorectal cancer cells (data not shown). Other groups have shown that morin reduces the incidence of lipopolysaccharide-induced septic shock (33) and suppresses the phorbol ester-induced transformation of hepatocytes (34). Morin has also been found to exert chemopreventive effects in a model of dimethylhydrazine-induced colon carcinogenesis (35). Here, we tested morin's anti-CSC effects based on the selective activation of STAT3 in the cancer stem cell population. Morin indeed reduced the cancer stem cell phenotype in human colorectal and breast cancers.

Telomeres function to protect DNA integrity, but unfortunately fragile sites and DNA damage can result at telomeric sites following disruption of telomere-telomerase homeostasis. MST-312 is a reversible telomerase inhibitor as it reduced telomerase activity and induced telomere dysfunction. We have observed that MST-312 clearly inhibited telomerase activity at $10 \mu \mathrm{M}$ in a gradient of $0,1,5$ and $10 \mu \mathrm{M}$ concentrations with human colorectal cancer cells (data not shown). It was recently reported that MST-312 exposure to breast cancer cells elevated level of double strand breaks (DSBs) based on the presence of the $\gamma$-H2AX proteins (36). This acute induction of DSBs resulted in growth arrest and was more evident in the metastatic breast cancer cell type MDA-MB-231 than MCF-7. We chose MST-312 because it inhibits telomerase and induce growth arrest selectively in aggressive tumor cells. MST-312 does not inhibit normal cell growth but inhibits effectively metastatic cancer cells (36). This makes it an attractive anticancer, anti-metastatic compound. Moreover, MST-312 is chemically more stable and more potent than its analog, green tea epigallocatechin gallate (EGCG) (17). MST-312 induced DNA damage at telomeres and elevated the level of DSBs leading to growth arrest. So, even after the MST-312 is removed, the inhibitory effects on telomere dynamics and telomerase will likely remain for certain time. In addition, MST-312 chemosensitized 5-FU in colorectal cancer cells and when combined with morin, showed well enhanced antitumor effects. 
We reasoned that if we targeted STAT3 and telomerase together, we could synergistically inhibit cancer stem cell traits since STAT3 regulates hTERT and telomerase activity is required for CSC growth. As morin inhibits STAT3 phosphorylation, it downregulates STAT3 target gene expression resulting in inhibition of CSC growth. Similarly, MST-312 inhibits telomerase and reduces the cancer stem cell population. One step further, we tested whether morin/MST-312 co-treatment augment 5-FU efficacy on the chemo-resistant colorectal cancer cells. In agreement with CSC trait reduction data, the co-treatment chemosensitized the 5-FU-resistant cancer cell lines. Taken together, this study suggests that novel targeted-therapy may be implemented using combination treatment for inhibiting STAT3 and telomerase. The in vivo animal study is underway to validate the reduction of tumor formation and metastasis with the morin/MST-312 combination treatment.

\section{Acknowledgements}

This study was supported by the National Institutes of Health (NIH, NCI, NIMHD, NCATS) grants to J.V. Vadgama: U54 CA143931, U54MD007598, UL1TR000124. S. Steven Chung is a scholar supported by the Clinical Research Education and Career Development by the NIMHD R25 MD 007610, pilot project award from U54 MD 007598 and Emerging scientist award from the Life Science Institute-CDU S21 MD 000103. We thank the division of cancer research and training members for their helpful suggestions. We also thank Dr Robert Gelfand for careful reading and proofreading of the manuscript.

\section{References}

1. Siegel R, Ma J, Zou Z and Jemal A: Cancer statistics, 2014. CA Cancer J Clin 64: 9-29, 2014

2. Luu C, Arrington AK, Schoellhammer HF, Singh G and Kim J: Targeted therapies in colorectal cancer: surgical considerations. J Gastrointest Oncol 4: 328-336, 2013.

3. Clarke MF, Dick JE, Dirks PB, Eaves CJ, Jamieson CH, Jones DL, Visvader J, Weissman IL and Wahl GM: Cancer stem cells - perspectives on current status and future directions: AACR Workshop on cancer stem cells. Cancer Res 66: 9339-9344, 2006.

4. Zhong Z, Wen Z and Darnell JE Jr: Stat3: A STAT family member activated by tyrosine phosphorylation in response to epidermal growth factor and interleukin-6. Science 264: 95-98, 1994.

5. Hirano T, Ishihara K and Hibi M: Roles of STAT3 in mediating the cell growth, differentiation and survival signals relayed through the IL- 6 family of cytokine receptors. Oncogene 19 2548-2556, 2000.

6. Turkson J and Jove R: STAT proteins: Novel molecular targets for cancer drug discovery. Oncogene 19: 6613-6626, 2000.

7. Azare J, Doane A, Leslie K, Chang Q, Berishaj M, Nnoli J, Mark K, Al-Ahmadie H, Gerald W, Hassimi M, et al: Stat3 mediates expression of autotaxin in breast cancer. PLoS One 6: e27851, 2011.

8. Dauer DJ, Ferraro B, Song L, Yu B, Mora L, Buettner R, Enkemann S, Jove R and Haura EB: Stat3 regulates genes common to both wound healing and cancer. Oncogene 24: 3397-3408, 2005.

9. Tseng LM, Huang PI, Chen YR, Chen YC, Chou YC, Chen YW, Chang YL, Hsu HS, Lan YT, Chen KH, et al: Targeting signal transducer and activator of transcription 3 pathway by cucurbitacin I diminishes self-renewing and radiochemoresistant abilities in thyroid cancer-derived CD133+ cells. J Pharmacol Exp Ther 341: 410-423, 2012
10. Chan KS, Sano S, Kiguchi K, Anders J, Komazawa N, Takeda J and DiGiovanni J: Disruption of Stat 3 reveals a critical role in both the initiation and the promotion stages of epithelial carcinogenesis. J Clin Invest 114: 720-728, 2004.

11. Bertorelle R, Rampazzo E, Pucciarelli S, Nitti D and De Rossi A: Telomeres, telomerase and colorectal cancer. World J Gastroenterol 20: 1940-1950, 2014.

12. Tatsumoto N, Hiyama E, Murakami Y, Imamura Y, Shay JW, Matsuura Y and Yokoyama T: High telomerase activity is an independent prognostic indicator of poor outcome in colorectal cancer. Clin Cancer Res 6: 2696-2701, 2000.

13. Liu Z, Li Q, Li K, Chen L, Li W, Hou M, Liu T, Yang J, Lindvall C, Björkholm M, et al: Telomerase reverse transcriptase promotes epithelial-mesenchymal transition and stem cell-like traits in cancer cells. Oncogene 32: 4203-4213, 2013.

14. Brown J, O'Prey J and Harrison PR: Enhanced sensitivity of human oral tumours to the flavonol, morin, during cancer progression: Involvement of the Akt and stress kinase pathways. Carcinogenesis 24: 171-177, 2003.

15. Manna SK, Aggarwal RS, Sethi G, Aggarwal BB and Ramesh GT: Morin (3,5,7,2',4'-Pentahydroxyflavone) abolishes nuclear factor-kappaB activation induced by various carcinogens and inflammatory stimuli, leading to suppression of nuclear factor-kappaB-regulated gene expression and up-regulation of apoptosis. Clin Cancer Res 13: 2290-2297, 2007.

16. Gupta SC, Phromnoi K and Aggarwal BB: Morin inhibits STAT3 tyrosine 705 phosphorylation in tumor cells through activation of protein tyrosine phosphatase SHP1. Biochem Pharmacol 85: 898-912, 2013.

17. Seimiya H, Oh-hara T, Suzuki T, Naasani I, Shimazaki T, Tsuchiya $\mathrm{K}$ and Tsuruo $\mathrm{T}$ : Telomere shortening and growth inhibition of human cancer cells by novel synthetic telomerase inhibitors MST-312, MST-295, and MST-1991. Mol Cancer Ther 1: 657-665, 2002

18. Serrano D, Bleau AM, Fernandez-Garcia I, FernandezMarcelo T, Iniesta P, Ortiz-de-Solorzano C and Calvo A: Inhibition of telomerase activity preferentially targets aldehyde dehydrogenase-positive cancer stem-like cells in lung cancer. Mol Cancer 10: 96, 2011.

19. Chung SS, Aroh C and Vadgama JV: Constitutive activation of STAT3 signaling regulates hTERT and promotes stem cell-like traits in human breast cancer cells. PLoS One 8: e83971, 2013.

20. Park JI, Venteicher AS, Hong JY, Choi J, Jun S, Shkreli M, Chang W, Meng Z, Cheung P, Ji H, et al: Telomerase modulates Wnt signalling by association with target gene chromatin. Nature 460: 66-72, 2009.

21. Hoffmeyer K, Raggioli A, Rudloff S, Anton R, Hierholzer A, Del Valle I, Hein K, Vogt R and Kemler R: Wnt/ $\beta$-catenin signaling regulates telomerase in stem cells and cancer cells. Science 336: 1549-1554, 2012.

22. Korsmeyer SJ: BCL-2 gene family and the regulation of programmed cell death. Cancer Res 59 (Suppl): S1693-S1700, 1999.

23. Kern SE, Kinzler KW, Bruskin A, Jarosz D, Friedman P, Prives C and Vogelstein B: Identification of p53 as a sequence-specific DNA-binding protein. Science 252: 1708-1711, 1991.

24. Abraham RT: Cell cycle checkpoint signaling through the ATM and ATR kinases. Genes Dev 15: 2177-2196, 2001.

25. Yamaguchi K, Shirakabe K, Shibuya H, Irie K, Oishi I, Ueno N, Taniguchi T, Nishida E and Matsumoto K: Identification of a member of the MAPKKK family as a potential mediator of TGF-beta signal transduction. Science 270: 2008-2011, 1995.

26. Tibbles LA and Woodgett JR: The stress-activated protein kinase pathways. Cell Mol Life Sci 55: 1230-1254, 1999.

27. Alnemri ES, Livingston DJ, Nicholson DW, Salvesen G, Thornberry NA, Wong WW and Yuan J: Human ICE/CED-3 protease nomenclature. Cell 87: 171, 1996.

28. Jacobs MD and Harrison SC: Structure of an IkappaBalpha/ NF-kappaB complex. Cell 95: 749-758, 1998.

29. Bracht K, Nicholls AM, Liu Y and Bodmer WF: 5-Fluorouracil response in a large panel of colorectal cancer cell lines is associated with mismatch repair deficiency. Br J Cancer 103: 340-346, 2010.

30. Garcia R, Bowman TL, Niu G, Yu H, Minton S, Muro-Cacho CA, Cox CE, Falcone R, Fairclough R, Parsons S, et al: Constitutive activation of Stat 3 by the Src and JAK tyrosine kinases participates in growth regulation of human breast carcinoma cells. Oncogene 20: 2499-2513, 2001. 
31. Takemoto S, Ushijima K, Kawano K, Yamaguchi T, Terada A, Fujiyoshi N, Nishio S, Tsuda N, Ijichi M, Kakuma T, et al: Expression of activated signal transducer and activator of transcription-3 predicts poor prognosis in cervical squamous-cell carcinoma. Br J Cancer 101: 967-972, 2009.

32. Wang X, Wang G, Zhao Y, Liu X, Ding Q, Shi J, Ding Y and Wang S: STAT3 mediates resistance of CD44(+)CD24(-/low) breast cancer stem cells to tamoxifen in vitro. J Biomed Res 26: 325-335, 2012.

33. Fang SH, Hou YC, Chang WC, Hsiu SL, Chao PD and Chiang BL: Morin sulfates/glucuronides exert anti-inflammatory activity on activated macrophages and decreased the incidence of septic shock. Life Sci 74: 743-756, 2003.
34. Hsiang CY, Wu SLand HoTY: Morin inhibits 12-O-tetradecanoylphorbol-13-acetate-induced hepatocellular transformation via activator protein 1 signaling pathway and cell cycle progression. Biochem Pharmacol 69: 1603-1611, 2005.

35. Sreedharan V, Venkatachalam KK and Namasivayam N: Effect of morin on tissue lipid peroxidation and antioxidant status in 1, 2-dimethylhydrazine induced experimental colon carcinogenesis. Invest New Drugs 27: 21-30, 2009.

36. Gurung RL, Lim SN, Low GK and Hande MP: MST-312 alters telomere dynamics, gene expression profiles and growth in human breast cancer cells. J Nutrigenet Nutrigenomics 7: 283-298, 2014. 